\title{
FINITE ELEMENT SIMULATION OF SPRINGBACK IN TRIP 780 ADVANCED HIGH STRENGTH STEEL
}

\author{
M. Safaei, W. De Waele, M. Abdel Wahab, P. De Baets \\ Ghent University, Laboratory Soete, Belgium
}

\begin{abstract}
This paper discusses the effects of mechanical anisotropy of TRIP 780 advanced high strength steel on the springback observed in sheet metal forming. A series of finite element analyses using the Hill's 48 transverse anisotropic yield model and a standard U-shape forming test based on the NUMISHEET'93 benchmark has been performed. A comparison of springback angles for different orientation of sheet strips relative to the rolling direction is presented. The results show that the amount of springback changes with respect to the orientation of the test samples.
\end{abstract}

Keywords Advanced High Strength Steel, Finite element model, Springback

\section{INTRODUCTION}

As new materials with higher strength are introduced to industry, the accurate simulation of springback in sheet forming becomes more essential. Springback has always been a focus of research in sheet metal forming. In spite of advances in finite element techniques, an accurate prediction of springback is still unsatisfactory. In this paper, the springback behavior of one type of advanced high strength steels, Transformation-Induced Plasticity (TRIP) steel, has been numerically investigated. Advanced high strength steels (AHSS) exhibit higher strength and formability, even when compared with conventional high strength steels. The only method of production of AHSS is through controlling the cooling rate from austenite or austenite plus ferrite phase; either on the runout table of the hot mill or in the cooling section of the continually annealing furnace [1]. As with all high-strength steels, springback is a concern with AHSS. Without appropriate compensation, the higher strength of the AHSS grades usually leads to more springback compared to conventional HSS.

Previous studies applied finite element technique on the evaluation of springback. For example, Azraq et al used finite elements for prediction of final shape and springback of TRIP 800 in stamping process [2]. Yuen noticed that different unloading schemes will affect the accuracy of the springback prediction [3]. Chen et al [4] applied finite elements and design of experiments to investigate the effects of variations in material, blank holder force and friction on the springback variation for an open-channel shaped part made of a dual phase (DP) steel. Panthi et al [5] carried out their simulation using a indigenous finite element code for prediction of springback in a typical sheet metal bending process. In the present work, finite element analysis of springback on the base of NUMISHEET'93 U-shape forming test [6] is presented.

\section{FINITE ELEMENT MODEL}

\subsection{Geometric Model}

The U-shaped cross-section introduced in NUMISHEET'93, shown Figure 1, was selected for this study [7]. The geometry used for springback measurement is shown in Figure 2. Springback assessment is performed by measuring the angles $\theta_{1}, \theta_{2}$ and the radius $\rho$; Where $\theta_{1}$ is the angle between the line " $a b$ ", (starting from point " $a$ " in the workpiece, $15 \mathrm{~mm}$ above the lowest part of the formed sheet metal, to point " $b$ " , intersection of a circle of $35 \mathrm{~mm}$ radius and a center coinciding with point " $a$ " with the sidewall of the workpiece) and any horizontal line (ox). Other measurements were performed by measuring the angle between " $a b$ " with the straight line "ef", and measuring the radius of a circle with an arc fitting the "acb" curve of the sheet strip, for $\theta_{2}$ and $\rho$, respectively. 


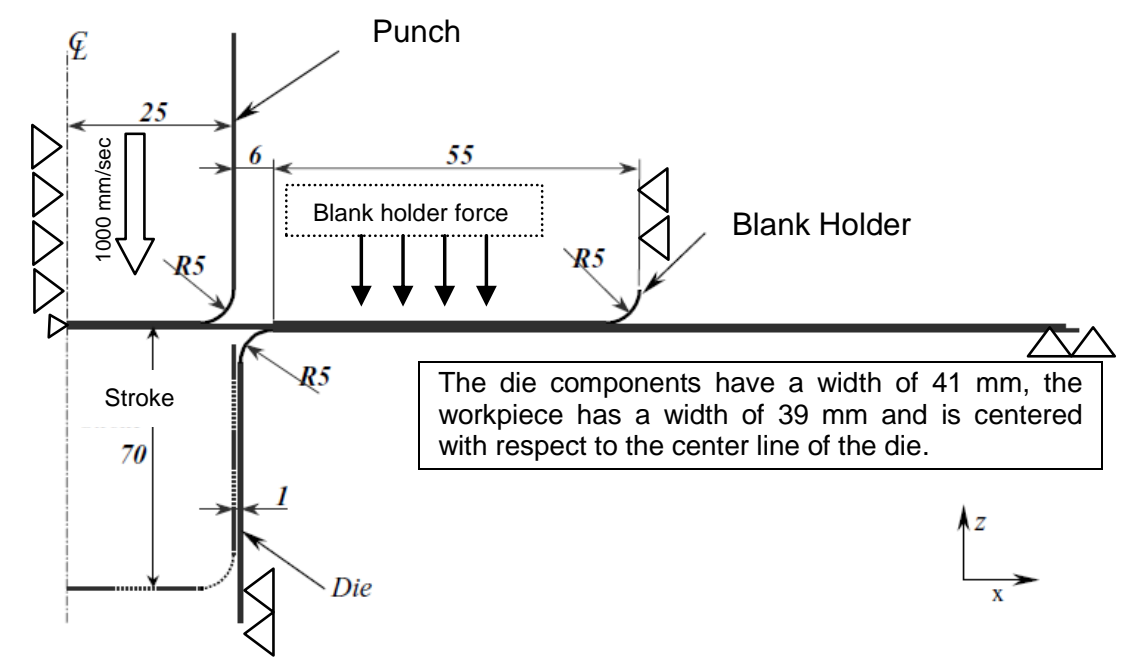

Figure 1. The NUMISHEET'93 benchmark geometry used for finite element springback analysis; Units: mm [7]

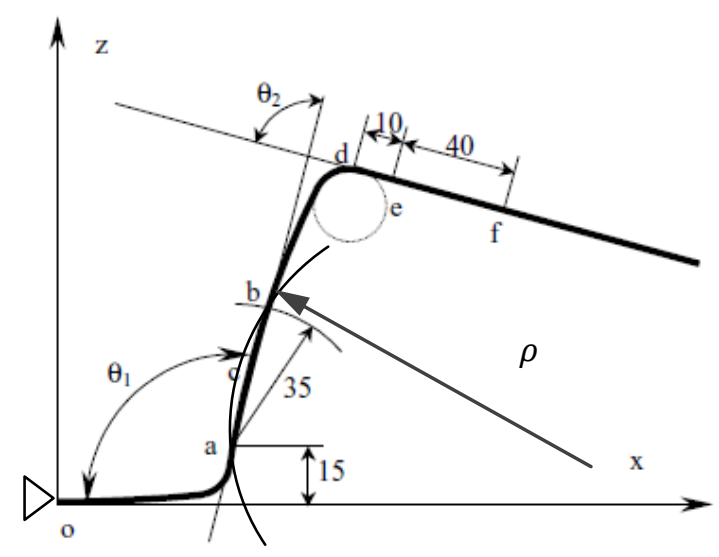

Figure 2. Variables used for springback measurement; Units: $\mathrm{mm}$ [7]

\subsection{Material Model}

The true stress versus true strain diagram of the sheet metal TRIP 780 for different orientations with respect to the rolling direction is shown in Figure 3 [8]. The change of orientation of polycrystalline grains due to the rolling process is the main reason of directional dependency of yield in the rolled sheet metals [9]. The flow stress equation of the TRIP 780 in the rolled direction and at a strain rate of $1.67 E-3$, obtained according to the International Standard ASTM E 646-07, can be described as a Hollomon power law as presented in Equation 1.

$$
\bar{\sigma}=1444 \bar{\varepsilon}^{0,208}
$$

Various yield functions have been used in the literature [10-13]. In this study, the Hill's 48 transverse anisotropic yield model has been used to describe the material's anisotropic behavior. This equation assumes materials with three orthogonal axes of anisotropy, $x, y$, and $z$ about which the properties have two-fold symmetry. The $y z, z x$, and $x y$ planes are planes of mirror symmetry. In a rolled sheet it is usual to take the $x-, y-$, and $z$-axes as the rolling direction, the in-plane transverse direction, and the sheet-plane normal. The theory also assumes equality of the tensile and compressive yield strengths in every direction 
[9]. Hill's 48 quadratic anisotropic yield function is expressed by equations 2 to 6 and its anisotropy ratios (width to thickness strain ratios) for the TRIP 780 material are presented in Table 1.
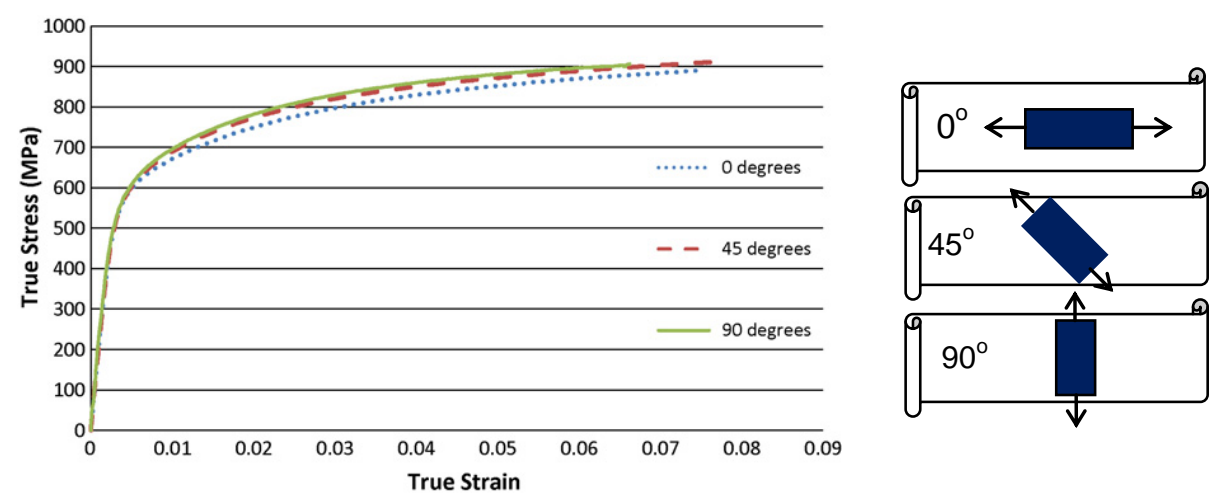

Figure 3. True stress- strain for TRIP 780 [8]

$$
\begin{gathered}
F\left(\sigma_{y y}-\sigma_{z z}\right)^{2}+G\left(\sigma_{z z}-\sigma_{x x}\right)^{2}+H\left(\sigma_{x x}-\sigma_{y y}\right)^{2}+2 L \tau_{x y}^{2}+2 M \tau_{z x}^{2}+2 N \tau_{x y}^{2}=k^{2} \\
F=\frac{R_{0}}{R_{90}\left(1+R_{90}\right)} \\
G=\frac{1}{1+R_{0}} \\
H=\frac{R_{0}}{1+R_{0}} \\
N=\frac{\left(R_{0}+R_{90}\right)\left(1+2 * R_{45}\right)}{2 R_{90}\left(1+R_{0}\right)}
\end{gathered}
$$

Where $\sigma_{\mathrm{xx}}, \sigma_{\mathrm{yy}}, \sigma_{\mathrm{zz}}, \tau_{\mathrm{xy}}, \tau_{\mathrm{zx}}$ and $\tau_{\mathrm{xy}}$ are the components of the Cauchy stress tensor defined in the orthotropic frame and F, G, H, L, M and $\mathrm{N}$ are the Hill coefficients that define the anisotropy and the $R_{0}, R_{45}$ and $R_{90}$ are the Lankford coefficients defined as the ratio of transverse to thickness strain in sheet strips with 0,45 and 90 degree material orientation relative to the rolling direction, respectively.

Table 1. Anisotropy ratios for TRIP 780 [2]

\begin{tabular}{|c|c|c|c|c|}
\hline$R_{0}$ & $R_{45}$ & $R_{90}$ & $\bar{R}$ & $\Delta R$ \\
\hline 0.498 & 0.872 & 0.583 & 0.70625 & -0.3315 \\
\hline
\end{tabular}

The coefficients of $\bar{R}$, normal plastic anisotropy, and $\Delta R$,planar plastic anisotropy, mentioned in Table 1 are:

$\bar{R}=\frac{R_{0}+2 R_{45}+R_{90}}{4}$

$\Delta R=\frac{R_{0}-2 R_{45}+R_{90}}{2}$

\subsection{Finite Element Simulation}

In the finite element code, elastic-plastic and rigid types of material were set for workpiece and dies (punch, blank holder and die), respectively

The geometries of dies and sheet strip were designed using SolidWorks ${ }^{\circledR}$ [14] and the CAD files used as the input geometries for the finite element code. Whereas the dimensions of the blank were $300 * 39 *$ $0.78 \mathrm{~mm}^{3}$, because of symmetric geometry of the blank only $150 \mathrm{~mm}$ of the sheet length was modeled. For more accurate results, a mesh with 40,000 tetrahedral elements was assigned to the workpiece (Figure 4). 
For illustration purpose and a better understanding of position of the blank, whole geometry of the blank is shown in Figure 4. A blank holder force of $5 \mathrm{kN}$ was included and the displacement speed of the punch was simulated as $1000 \mathrm{~mm} / \mathrm{sec}$ in the negative z- direction. Contact between workpiece and rigid dies was modeled using a 0.05 coulomb friction. The used coefficient of friction for specific sheet metal forming conditions, using lubrication and coated dies, produces reasonable results [15].

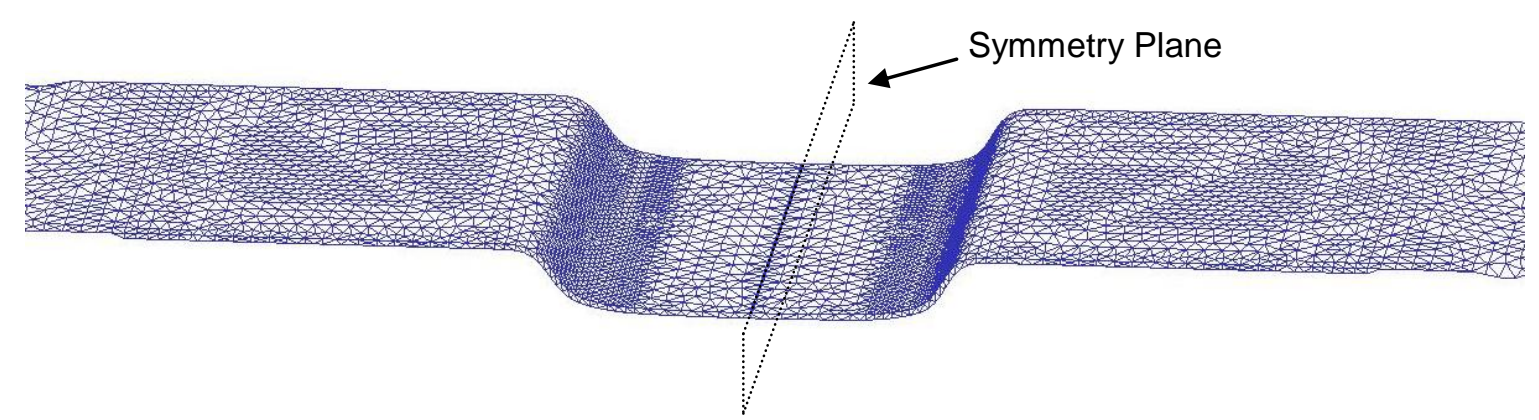

Figure 4. Tetrahedral mesh assigned to workpiece (due to symmetrical geometry of the part, just the left part of workpiece was used for simulation)

\section{RESULTS}

For an ideal sheet metal formed part, no springback is desired. The wall of the U-shape is expected to be flat $(\rho \rightarrow \infty)$, and the angles $\theta_{1}$ and $\theta_{2}$ are desired to be $90^{\circ}$. Previous research $[7,16]$ concluded that as the yield stress increases, the elastic return increases. Figure 3 shows that the yield stress slightly increases with an increased angular deviation from the rolling direction. Therefore the amount of springback is expected to increase as the rolling direction increases (Figure 5). This conclusion can be observed in Table 2. This general result is supported by other research for different high strength steels [7]. The results show that with increase of springback, $\rho$ decreases whereas $\theta_{1}$ and $\theta_{2}$ increase (Table 2).
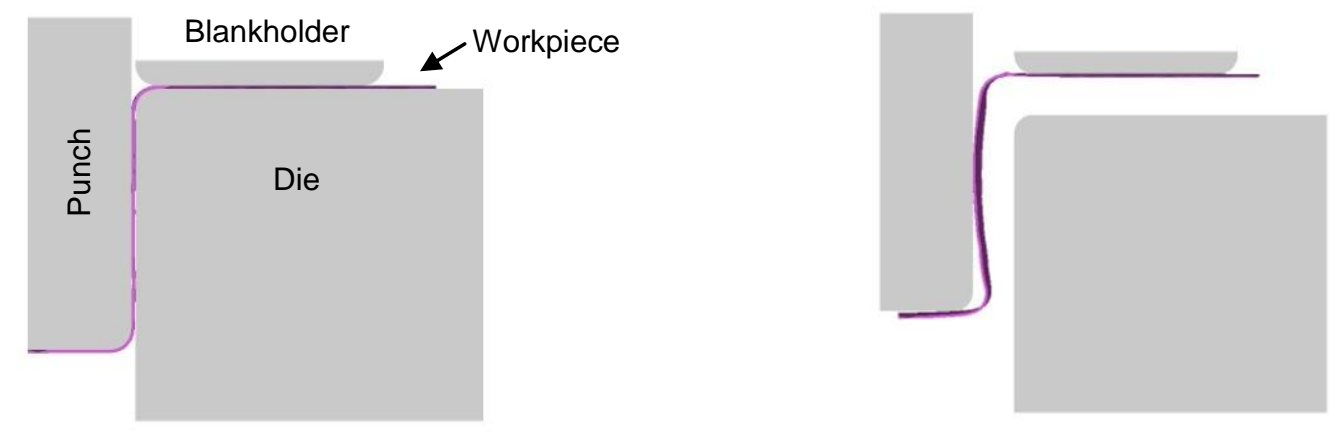

Figure 5. Position of die, punch, blank holder and workpiece before and after load releasing, left to right respectively

To simulate the elastic recovery of the workpiece, after the final step of forming and achieving the desired punch movement, unloading steps were done. During these steps, the contact between the workpiece and rigid parts diminishes and finally all the internal stress components of the workpiece are equilibrated and the springback can be measured (Figure 6).

Table 2. Numerical results of springback

\begin{tabular}{|r|c|c|c|}
\hline & $\theta 1$ & $\theta 2$ & $\rho(\mathrm{mm})$ \\
\hline $0^{\circ}$ & 87 & 87 & 132 \\
\hline $45^{\circ}$ & 88 & 88 & 128 \\
\hline $90^{\circ}$ & 92 & 95 & 63 \\
\hline
\end{tabular}



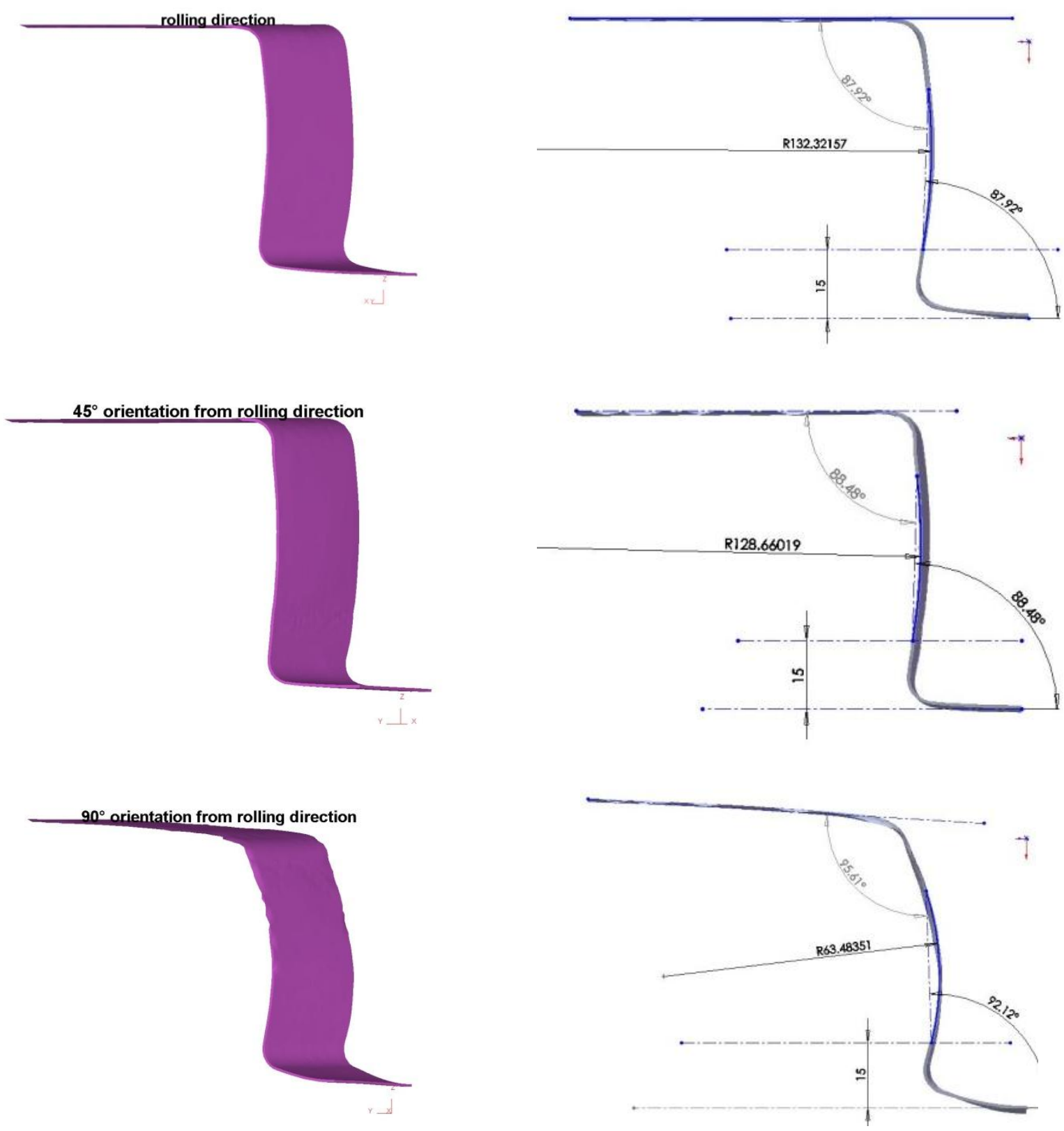

Figure 6. Finial shape after equilibration of internal stresses in blank strips with 0,45 and 90 degree direction from rolling direction from top to down respectively

\section{CONCLUSIONS}

In the current study the effects of mechanical anisotropy of TRIP 780 on the springback was discussed. A series of finite element analyses using the Hill's 48 transverse anisotropic yield model and a standard Ushape forming test based on NUMISHEET'93 has been performed. The results show that as the yield stress increases with increased angular deviation from the rolling direction, the elastic return increases. The variations in springback from the $0^{\circ}$ to $90^{\circ}$ material orientations show considerable variation. These results clearly show how anisotropy contributes to springback and the possibility of observing these effects using finite element analysis. The next step of the current project will be the implementation of other advanced anisotropic yield functions and mixed isotropic-kinematic hardening rules into finite element code and comparison with experimental results.

\section{NOMENCLATURE}

$\theta 1 \quad$ Angle between ox and ab (Figure 2). 
$\theta_{2} \quad$ Angle between ab and ef (Figure 2).

$\rho \quad$ Radius of a circle through $\mathrm{a}, \mathrm{b}$ and $\mathrm{c}$ (Figure 2).

a $\quad 15 \mathrm{~mm}$ from ox (Figure 2).

$b \quad 35 \mathrm{~mm}$ from point a (Figure 2).

$c \quad$ Middle point of the straight line ab (Figure 2).

$d \quad$ End of the Die's curvature (Figure 2)

$e \quad 10 \mathrm{~mm}$ from d (Figure 2).

$f \quad 40 \mathrm{~mm}$ from e (Figure 2).

\section{ACKNOWLEDGEMENTS}

The authors would like to acknowledge the financial support of BOF (grant nr. 01J10608) and FWO Vlaanderen (grant nr. 1.5.247.08).

\section{REFERENCES}

[1] Advanced high strength steel (AHSS) application guidelines. www.worldautosteel.org,(Version 4.1), June 2009.

[2] S.A. Azraq, et al., Springback prediction with FEM analysis of advanced high strength steel stamping process, in Intelligent Production Machines and Systems, Elsevier Science Ltd: Oxford. p. 264-269, 2006.

[3] W.Y.D. Yuen, Springback in the stretch-bending of sheet metal with non-uniform deformation. Journal of Materials Processing Technology, 22(1): p. 1-20, 1990.

[4] P. Chen and M. Koç, Simulation of springback variation in forming of advanced high strength steels. Journal of Materials Processing Technology, 190(1-3): p. 189-198, 2007.

[5] S.K. Panthi, et al., Finite Element Analysis of sheet metal bending process to predict the springback. Materials \& Design, 31(2): p. 657-662,

[6] NUMISHEET'93, in Proceedings of the second international conference of numerical simulation of 3-D sheet metal forming processes, Isehara, Japan, 1993.

[7] C. Gomes, O. Onipede, and M. Lovell, Investigation of springback in high strength anisotropic steels. Journal of Materials Processing Technology, 159(1): p. 91-98, 2005.

[8] A. Nasser, et al., Determination of the flow stress of five AHSS sheet materials (DP 600, DP 780, DP 780-CR, DP 780-HY and TRIP 780) using the uniaxial tensile and the biaxial Viscous Pressure Bulge (VPB) tests. Journal of Materials Processing Technology, 210(3): p. 429-436,

[9] W.F. Hosford and R.M. Caddell, Metal forming : mechanics and metallurgy. 2007, New York, NY: Cambridge University Press, 2007.

[10] D. Banabic, et al., An anisotropic yield criterion for sheet metals. Journal of Materials Processing Technology, 157-158: p. 462-465, 2004.

[11] F. Barlat, D.J. Lege, and J.C. Brem, A six-component yield function for anisotropic materials. International Journal of Plasticity, 7(7): p. 693-712, 1991.

[12] R. Hill, Constitutive modelling of orthotropic plasticity in sheet metals. Journal of the Mechanics and Physics of Solids, 38(3): p. 405-417, 1990.

[13] P. Van Houtte, Application of plastic potentials to strain rate sensitive and insensitive anisotropic materials. International Journal of Plasticity, 10(7): p. 719-748, 1994.

[14] SolidWorks, Dassault Systems, SolidWorks Corp: Santa Monica,CA.

[15] B.H. Lee, Y.T. Keum, and R.H. Wagoner, Modeling of the friction caused by lubrication and surface roughness in sheet metal forming. Journal of Materials Processing Technology, 130-131: p. 60-63, 2002.

[16] J.J. Stien. The effect of process variables on sheet metal springback. in Proceedings of the International Body Conference and Exposition. Detroit, USA, 1998. 